\title{
THE REASON FOR LOW ACCESS OF HIGH-QUALITY EDUCATION AND MEDICAL SERVICES
}

\section{GIORGI JVARIDZE}

\section{PhD student}

Samtskhe-Javakheti State University, Georgia

gia.giorgi.1962@gmail.com

Abstract. In the article - "The reason for low access of high-quality education and medical services" - the reasons for the rise of the education crisis in the world in the 70s, low results in the education system in Georgia, reduction of the number of pupils compared to previous years, etc. are discussed. In 1999-2000, 714400 pupils were studying in secondary schools of Georgia and in 2017-2018 only 575 100. Education does not have access not only for the Georgian population, but moreover, for the Subsahari, the Asian and Latin American population. There are four classes (and lower ones) educated people there and the share of educated population is very high.

The same situation is in healthcare. Inequality in Medical Healthcare has wide scales in poor countries. Children's and women ss mortality there are higher than in rich countries. Georgia is a poor country and the situation is the same in real, but the statistics office of Georgia does not publish this information in public as regarding the poor and rich people. But the fact that in 2000 the mortality rate for every 1,000 people in Georgia was 9, 8 units in 2000, and in 2017 - 12, 8 units, means that access to quality medical services has not been reduced but increased.

The article ends with a summary conclusion in which the author encourages the authorities to take care of the reduction of inequalities in the population.

\section{KEYWORDS: INEQUALITY, EDUCATION, REVENUES, MEDICAL SERVICE.}

For citation: Jvaridze, G., (2020). The Reason for Low Access of High-Quality Education and Medical Services. Globalization and Business, 10. 295-297. https://doi.org/10.35945/gb.2020.10.040

\section{INTRODUCTION}

Inequality in the country is not only measured by income inequality. Income inequality leads to inequality in education, health care, and wealth accumulation. In this article, we will not focus on the accumulation of wealth, because in our opinion, it would be better if people considered wealth not material possessions but education, culture and health and aspired to provide for them.

\section{Inequality in education.}

Human civilization is created from the knowledge gained as a result of human education. The aspiration to get education is inside, in the person. He wants to know the world and establish himself in it.

"It is a paradox, but it is a fact," a Georgian scientist G. Jolia writes and argues that in the modern information society, when people are given far more opportunities to get education, there is a worldwide education crisis, which is then manifested in negative trends (Jolia, 2016, p. 92):

- The number of illiterates is increasing;

- The quality of education is declining;

- The gap between education and science is widening;

- The student (student) is gradually diverted from the education process.
This crisis of education in the world began in the 70s. On the basis of this, the French scientist F. Coombs named three reasons (Coombs, 1970, p. 293):

1. The existing educational network does not meet the needs of the masses for education.

2. The education system is unable to meet the new requirements due to lack of financial resources.

3. The internal structure of the education system is inert.

History has passed the time when education was focused on «loading» information in the mind of an individual (pupil, student). In today's education it has been replaced by a creative approach. Therefore, the accumulation of "a lot» of knowledge is not in the foreground, but deep thinking. Great reforms have been carried out in this direction in the education system of Georgia as well, but what? Here is what Professor R. Asatiani writes about it: «Reforming the education system has not improved the quality of education in Georgia, moreover, it has even worsened it in some respects» (Asatiani, 2013:133).

Now the question is: do all the educational institutions of the country meet this requirement or not? This question is answered in the article "Poverty Issues in Georgia» published in the scientific journal "Globalization and Business"., The Doctor of Economics, an Academician of the Georgian Academy of Economic Sciences - Kvaratskhelia writes: «One of the main reasons for this is the low level of development 
of education and science» ("Globalization and Business», 2017:137), And if it satisfies, can all pupils (students) get education there? We ask this question because the schools that have been able to transform and establish a new educational model according to the requirements of the "Grand Charter of Universities» adopted in Bologna (Italy), are very few in the world, education there is expensive and only children from financially rich families have access to them. "Due to low financial opportunities, only a small group is given the opportunity to study in foreign universities through exchange programs," writes Professor V. Sartania (Sartania, 2013:459). This is the case everywhere where incomes are unequally distributed among the population. Georgia is such a country.

However, the amount of income of the population is directly related to their education. Getting a good education requires a lot of investment. The IMF has conducted research on this issue in Europe, Latin America, Asia and sub-Saharan Africa. The aim of the study was to determine the proportion of the population aged 20-24 with an education of less than
4 classes in the poor and rich population. See this study in Figure 1 (Statistical Yearbook of Georgia, 2019:66).

According to this picture, in sub-Saharan Africa (as it is known, sub-Saharan Africa is the poorest region of Africa) a survey of $20 \%$ of the poor population found that $60 \%$ of them had no 4 th grade education, $15 \%$ of its rich population was in the same situation. In other regions, these figures were: $40 \%$ and $10 \%$ in Asia, respectively; In Latin America - 30\% and 5\%; In Europe $-1 \%$ and $0 \%$.

It is known that European countries are mainly highly developed countries, and that their income distribution inequality coefficients are also low (0.27-0.30). This allows us to conclude that this has led to a $1 \%$ of Europeans with 4 grades of education in the poor and the rich - $0 \%$. Compared to Europe, Latin America is also poorer, and so is Asia. That is why $40 \%$ of the poor population in Asia and $30 \%$ in Latin America do not even have 4 th grade knowledge. Therefore, we make an even more logical conclusion - the poorer the country, the greater the share of people without primary education (0-4 years of education) is in its poor and rich.

Figure 1. Population with less than four classes of education. Weight ( 1 indicates $20 \%$ of the poor, 2 indicates $20 \%$ of the poor)

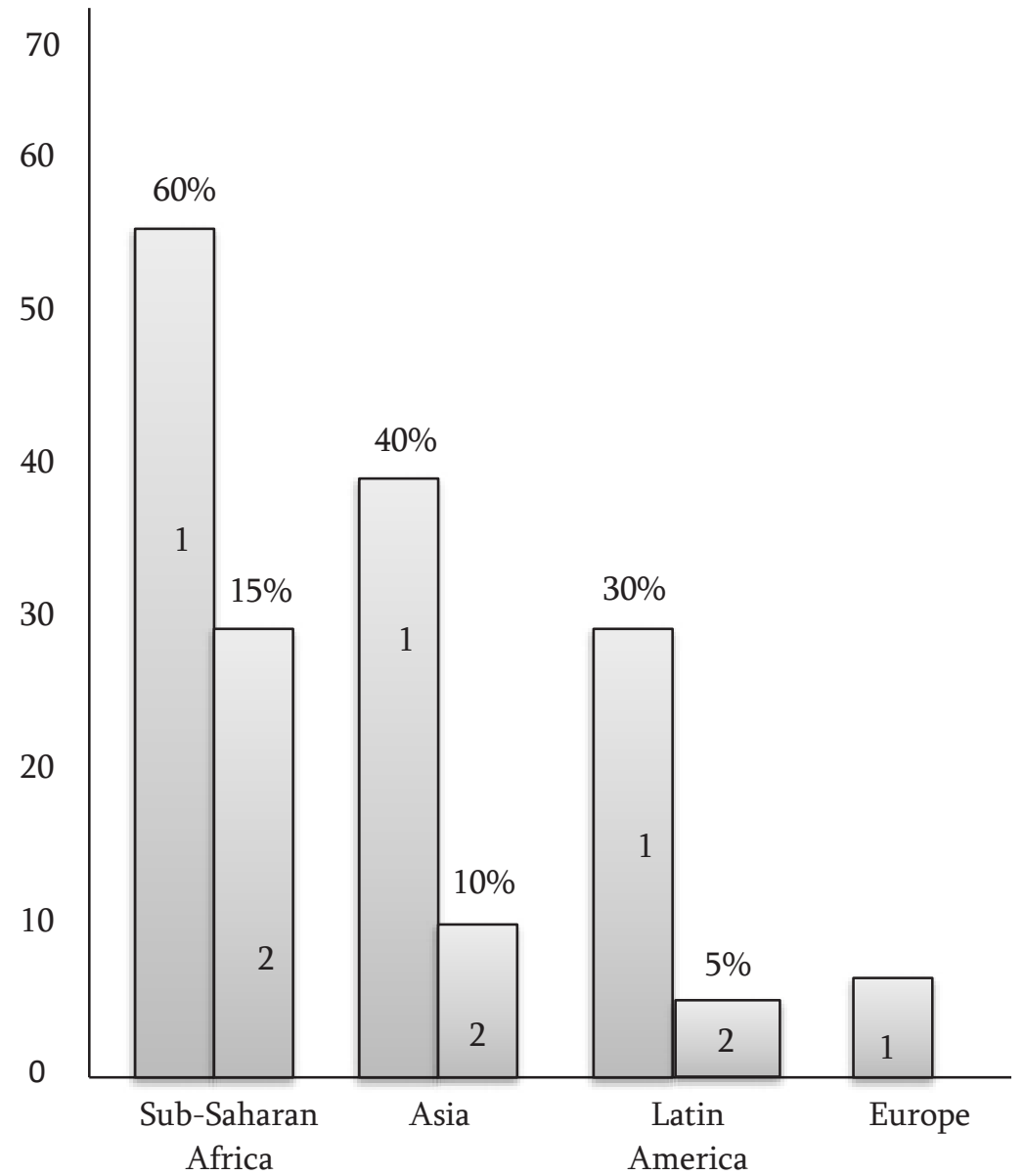

Signs:

1 - One-fifth of the poorest

2 - One-fifth of the richest 
We have begun to study this issue to show that the poor do not have access to education and that economic inequality creates inequality in education as well. However, if we look at the graph above, we will see that in all other regions except Europe - Asia, Sub-Saharan Africa and Latin America, the wealthiest segments of the population have up to 4 grades of education. It is difficult to explain this fact, but since it does not happen in civilized Europe, we must explain this fact by the low culture of the population of those regions.

There is no big improvement in Georgia either. In the 1999-2000 academic year, there were 714,400 students in secondary schools, and in the 2017-2018 academic year, there were only 575,200 students, which is $20 \%$ less (Statistical Yearbook of Georgia, 2019:66). How can we explain this situation, if not by the fact that poor families do not have the money to send their children to school (to buy books, clothes and shoes, etc.)? Of course, there are other reasons for this - the birth rate, marriages have been decreased, the emigration of young people from Georgia has been increased, and so on. But one of the reasons for low education is definitely the poverty of the population of Georgia.

Thus, lack of access to quality education is also due to poverty, and poverty is caused by unequal distribution of income among the population.

\section{Inequality in medical care.}

The same goes for health care. Here, correlation with income is high as well. Studies by the same IMF have found that inequality in health outcomes is widespread in developing countries, with access to it almost equal in rich and poor in developed countries. Infant mortality is twice as high in poor households in developing countries as in rich households in the same country. The situation is similar in female mortality. The only thing that was observed in developed countries was that income had a greater impact on people's life expectancy than was observed a generation ago. This has been particularly noted in the US (Murray, Lopez, Alvarado, 2013:591-606).

The IMF also found that in healthy societies with low female mortality, income inequality was lower. This finding proves that because of the fact that families have a normal income, women in the family can receive qualitative medical care. Precisely because the income inequality rate in Georgia is higher than in our neighboring countries, so the level of population satisfaction with health care compared to neighboring countries is the lowest in Georgia and it is - 50\%. At such times, it is $56 \%$ in Russia, $82 \%$ in Iran, $82 \%$ in Turkey, $68 \%$ in Azerbaijan and 53\% in Armenia (Calculated according to UN data., 2012:141-147; 176-179).

This situation of the population of Georgia makes us think that the government of the country should take active measures to reduce poverty. In the socio-economic development strategy of Georgia - «Georgia - 2020» these measures are clearly and distinctly listed and their implementation has been started. One such is the launch of the Universal State Medical Insurance Program in 2013 (Government of Georgia, 2013:59-67), which covered almost the entire population of Georgia and began to gradually reduce the out-of-pocket payment for treatment.

\section{Summary}

Discussing the problem posed in the article, we make the conclusion that the unequal distribution of income leads to the division of the population is not only the poor and the rich, but also into the uneducated and the educated people, the sick and the healthy ones.

The wealth of the country is people with education and ability, not only healthy people, and material wealth. Georgia should strive for that. At such times, inequality in the incomes of the population does not even decrease, but deepens, which means more uneducated and more sick people, who are uneducated and sick because they are so poor.

\section{REFERENCES}

Jolia, G. (2016). Creative Development: Education, Knowledge, Action, Monograph, Tbilisi.

Coombs, F., (1970). Crisis of education in the modern world: systematic analysis, per. with English, Progress, 293.

Asatiani, R. (2013). Stages of World Economic Development and Economic Policy of Georgia, Georgian Academy of Economic Sciences, Proceedings 11, Tbilisi.

Sartania, V. (2013). Education Reform and Its Consequences in Georgia, Georgian Academy of Economic Sciences, Proceedings 11, Tbilisi.

Statistical Yearbook of Georgia, Tbilisi. (2000), 87;

Statistical Yearbook of Georgia, Tbilisi. (2019), 66;

Murray, C., Lopez A. and Alvarado M., (2013). The State of US Heanth, 1990-2000: Burden of Aiseases, Injaries and Risk Factors. The journals of the American Medical Association 310 (6): 591-606;

Calculated according to UN data: Human Development Report, M., 2012, 141-147; 176-179;

Socio-economic development strategy of Georgia - Georgia - 2020, Government of Georgia, Tbilisi, 2013, 59-67;

Castello_Climent, A., and Domenech, R., (2014). Capital and Income Inequality Some Facts and Some Puzzles.

Stiglitz J., (2012). The Price of Inequality: How Todays Divided Sociality Endangers Our Future. New-York: www.Nor-ton;

Milanovic, B., (2013), Global Income Inequality by the Numbers: in History and Now. Global Policy 4 (2): 198-208;

Kvaratskhelia, M. (2017). Poverty issue in Georgia. Globalization and Business. 3, 137-141. 